\title{
Design and Analysis of a Slanted Strapon Nose Cone (SSNC) of an Advanced Launch Vehicle
}

\author{
Athira B.Krishnan ${ }^{1}$, Prashanthan A. ${ }^{2}$, Basil Sabu ${ }^{3}$ \\ ${ }^{1}$ (Department of Civil Engineering, Mar Athanasius College of Engineering, Kerala, India) \\ ${ }^{2}$ Scientist/Engineer, Vikram Sarabhai Space Centre, Kerala, India) \\ ( ${ }^{3}$ Asst. Professor, Dept. of Civil Engineering, Mar Athanasius College of Engineering, Kerala, India)
}

\begin{abstract}
Launch vehicles are used to transport satellite or space craft into space. To minimize the aero acoustic and aerodynamic loads, the nose cones are slanted to an angle on free side and straight on the interference side in advanced launch vehicles. Objective of this paper is to design and analyze nose cone region of a typical launch vehicle using integrally stiffened panel concept, made of aluminium alloy material. The first part of the present work is to make the optimum design of a slanted SNC structure and the second is to verify the detailed design through finite element method. Linear static stress analysis, buckling analysis and free vibration analysis of the finalized design is carried out using finite element analysis software NISA. Aerodynamic pressure distribution over the surface is generated using computational fluid dynamic analysis code PARAS $3 D$. Static, dynamic and buckling analysis results are presented here. Optimum design based on the integrally stiffened panel construction is compared with the design by combination of stiffened skin with bulkheads and isogrid type of construction.
\end{abstract}

Keywords: Integrally Stiffened Panel, Launch Vehicle, Slanted Strapon Nose Cone.

\section{Introduction}

India has made tremendous studies in launch vehicle technology to achieve self-reliance in satellite launch vehicle programme with the operationalization of PSLV and GSLV. To minimize the aero acoustic and aerodynamic loads on the vehicle, the slanted strap on nose cone with $25^{\circ}$ on the free side and straight on the interference side are selected based on various studies. The change in pressure rise on core will be more for slanted nose cone. But the zone of influence is more in regular nose cones. Appreciable weight savings are possible through the integral section design which also develops high resistance to buckling loads. This method improved performance through smoother exterior surfaces by reduction in number of attachments and nonbuckling characteristics of skin. Design of structural components has to meet specific requirements which influence the complexity of its structure and the materials used in its construction. Aluminium, blended with small quantities of other metals is used on most types of aircraft because it is lightweight and strong. AA2014 aluminium alloy is an aluminium-based alloy often used in the aerospace industry.(1) It is easily machined in certain tempers, and among the strongest available aluminium alloys, as well as having high hardness.

\section{Slanted Strapon Nose Cone Configuration}

The non-dimensional parameters of the SSNC selected for the present study is described here. The base diameter $\mathrm{D}$ is selected as reference dimension for this configuration. Aft End (AE) ring is a cylindrical structure with inclined top surface and tangential to the conical section. Nose cone is a truncated cone with non-parallel top and bottom surfaces also tangential to the nose cap and AE ring at all interfacing location. SSNC having an overall height of $1.68 \mathrm{D}$ and fore end of the cone is covered by a spherical cap of radius $0.23 \mathrm{D}$. The $\mathrm{AE}$ ring has a height of $0.25 \mathrm{D}$ at straight side and $0.36 \mathrm{D}$ on the other side due to the slanted configuration as shown in Fig. $1(\mathrm{a})$.

\section{Structural Limit Loads}

Vehicle load includes aerodynamic forces, thrust load and inertia loads etc. Inertia is often masked by the effects of friction and air resistance, both of which tend to decrease the speed of moving objects. The aerodynamic loads act in a direction normal to the surface. Based on the pressure distribution on the structure obtained from the computational fluid dynamics results for the most critical aerodynamic condition the structural limit loads computed are used for preliminary design of the components. The thrust load and associated inertia loads are available from the trajectory analysis. The integrated pressure and inertia loads with appropriate differential pressure and off nominal parameters are used for the generation of station loads. The equivalent axial force for thin circular cross section is also included in Table 1 with other force components. 

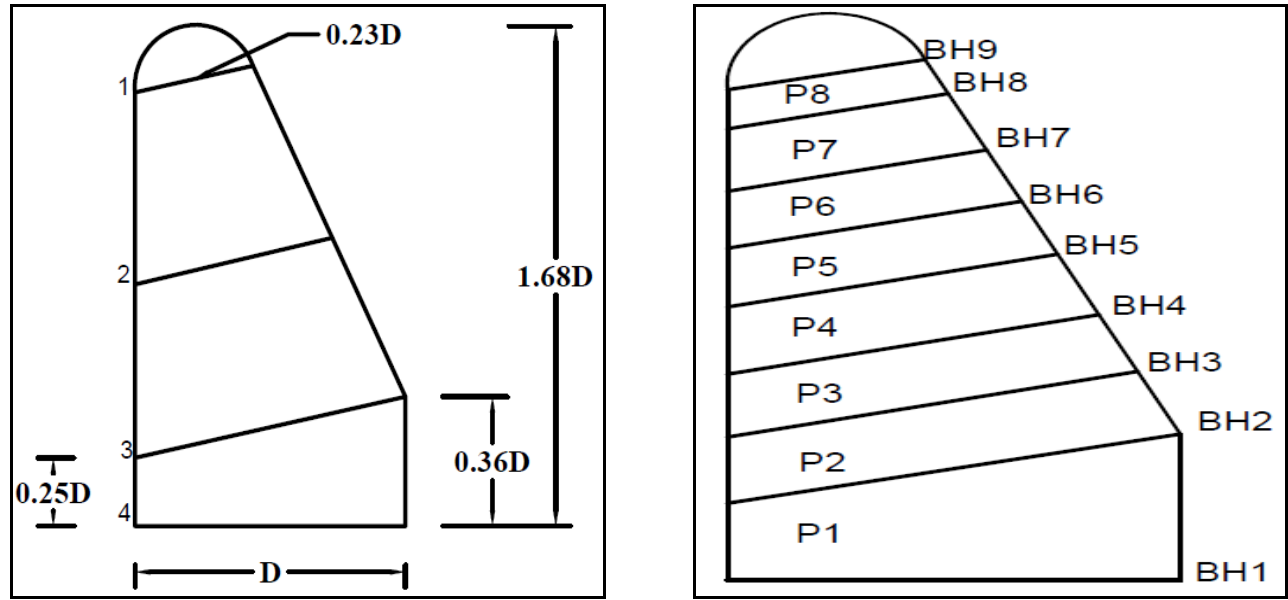

Fig. 1. (a) Strapon Configuration; (b) Arrangement of Bulkheads and Panels

Table 1. Structural Limit Loads on Slanted Strapon Nose Cone

\begin{tabular}{|l|l|l|l|l|}
\hline \multirow{2}{*}{ Location } & $\begin{array}{l}\text { Axial } \\
\text { Force }\end{array}$ & $\begin{array}{l}\text { Shear } \\
\text { force }\end{array}$ & $\begin{array}{l}\text { Bending } \\
\text { Moment }\end{array}$ & $\begin{array}{l}\text { Equivalent } \\
\text { Axial Force }\end{array}$ \\
\cline { 2 - 5 } & $\mathbf{k N}$ & $\mathbf{k N}$ & $\mathbf{k N m}$ & $\mathbf{k N}$ \\
\hline 1. Nose Cap & 12.3 & 84.5 & 0.2 & 13.4 \\
\hline 2. Nose cone (Top) & 29.1 & 175.0 & 1.0 & 31.2 \\
\hline 3. Nose cone (Bottom ) & 65.2 & 299.7 & 18.8 & 88.3 \\
\hline 4. Nose cone Aft End Ring & 89.7 & 300.0 & 87.2 & 198.7 \\
\hline
\end{tabular}

\section{Structural Layout}

The structural frame of SSNC consists of eight panels, four longerons and nine bulkheads. Longerons are provided at $90^{\circ}$ apart starting from the straight side. Bulkheads are provided for the stability of the longerons and panels. The number of bulkhead is arrived at to stabilize the structure from the overall compressive load. The spacing of the bulkhead is decided based on buckling strength requirements of the panels as well as functional requirements.

\subsection{Integrally Stiffened panel}

The panel is divided into eight segments with an equal spacing of $600 \mathrm{~mm}$ as shown in Fig. 1(b). The design values are obtained from the limit loads acting on structure as shown in Table 1 by applying a design load factor of 1.25. The panel is designed based on the ultimate design concept so as to resist the shear and tensile loads as well as to increase the buckling and failing stress (2). The integrally stiffened panels are optimally designed by keeping angle between stringers as $2^{0}$ with 1 × $16 \mathrm{~mm}$ size stringers along the longitudinal direction of panel.

\subsection{Nose Cap}

Nose cap is designed as monocoque construction with uniform thickness of $2 \mathrm{~mm}$. (3)

\subsection{Bulkhead Design}

Bulkheads are provided at $600 \mathrm{~mm}$ interval and are designed as 3D beam subjected to all six force components. The beam results are taken for the design of 'I' section bulkheads shown in Fig. 2(a) at each location of bulkheads. The limit loads for the design of bulkhead BH2 is given in Table 2. The geometric configuration of bulkheads are given in Table 3, are designed as slender compression beams (3). The I section bulkheads are fastened using rivets or screws with all design considerations of rivets (5). Sufficient design margin is ensured during the design process.

Table 2. Design Values of Bulkheads - Typical at BH2

\begin{tabular}{|l|l|l|}
\hline Results & Limit Load & Design value \\
\hline Axial Force, $\mathrm{Fx}(\mathrm{kN})$ & 65.0 & 89.4 \\
\hline Shear force, $\mathrm{Fy}(\mathrm{kN})$ & 35.3 & 48.5 \\
\hline Shear force, $\mathrm{Fz}(\mathrm{kN})$ & 296.9 & 408.2 \\
\hline Twisting Moment, $\mathrm{Mx}(\mathrm{kNm})$ & 39.2 & 53.9 \\
\hline Bending Moment, $\mathrm{My}(\mathrm{kNm})$ & 19.5 & 26.8 \\
\hline Bending Moment, Mz (kNm) & 10.3 & 14.0 \\
\hline
\end{tabular}


Table 3. Preliminary Design of Bulkheads

\begin{tabular}{|l|l|l|l|l|}
\hline Bulkhead Id & $\begin{array}{l}\text { Width, b } \\
(\mathbf{m m})\end{array}$ & $\begin{array}{l}\text { Thickness of Web, } \mathbf{t}_{\mathbf{w}} \\
(\mathbf{m m})\end{array}$ & $\begin{array}{l}\text { Overall Depth, D } \\
(\mathbf{m m})\end{array}$ & $\begin{array}{l}\text { Thickness of Flange, } \mathbf{t}_{\mathbf{f}} \\
(\mathbf{m m})\end{array}$ \\
\hline BH1 & 250 & 16 & 300 & 12 \\
\hline BH2 & 250 & 16 & 300 & 12 \\
\hline BH3 & 200 & 12 & 300 & 10 \\
\hline BH4 & 150 & 12 & 300 & 10 \\
\hline BH5 & 150 & 12 & 300 & 10 \\
\hline BH6 & 110 & 12 & 280 & 10 \\
\hline BH7 & 110 & 12 & 280 & 10 \\
\hline BH8 & 90 & 10 & 150 & 8 \\
\hline BH9 & 90 & 10 & 150 & 8 \\
\hline
\end{tabular}

Table 4. Design Values of Longerons

\begin{tabular}{|l|l|l|}
\hline \multicolumn{1}{|c|}{ Results } & Limit Load & Design value \\
\hline Axial Force, Fx $(\mathrm{kN})$ & 13.0 & 17.9 \\
\hline Shear force, Fy $(\mathrm{kN})$ & 1.9 & 2.7 \\
\hline Shear force, Fz $(\mathrm{kN})$ & 0.6 & 0.8 \\
\hline Twisting Moment, Mx (kNm) & 0.01 & 0.01 \\
\hline Bending Moment, My (kNm) & 0.5 & 0.1 \\
\hline Bending Moment, Mz (kNm) & 0.1 & 0.2 \\
\hline
\end{tabular}

\subsection{Longeron Design}

The axial loaded member longeron is also considered as slender column with a $\mathrm{T}$ section as shown in Fig. 2(b). Loads used for the design of longerons are given in Table 4. (3)
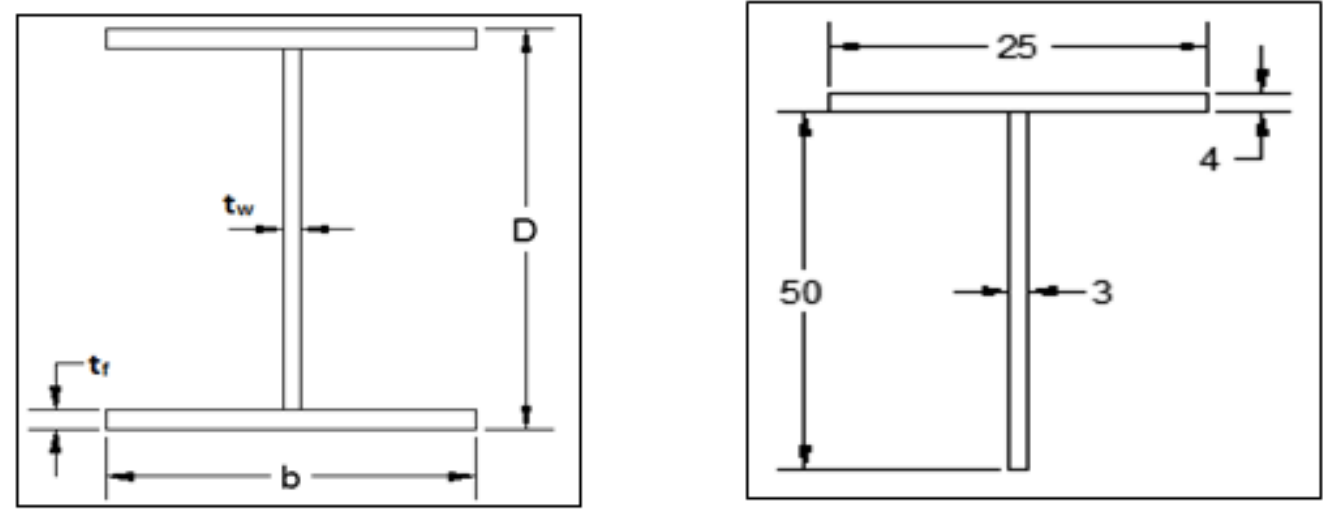

Fig. 2. (a) Typical Bulkhead Drawing; (b) $\mathrm{T}$ - Section Longeron

\section{Finite Element Modelling and Boundary Condition}

The skin and bulkheads are discretized with 4 node general quadrilateral shell element with an element size of $30 \mathrm{~mm}$ by keeping an aspect ratio nearly 1 . The angle between stringers is $2^{0}$ and is created at region between bulkheads with two noded beam elements. There are total number of 153057 numbers of nodes and 205433 elements in the entire slanted SNC model. The three displacements are restrained at each node of the aft end ring as boundary condition. Isometric view of modeled components in NISA is shown in Fig. 3.

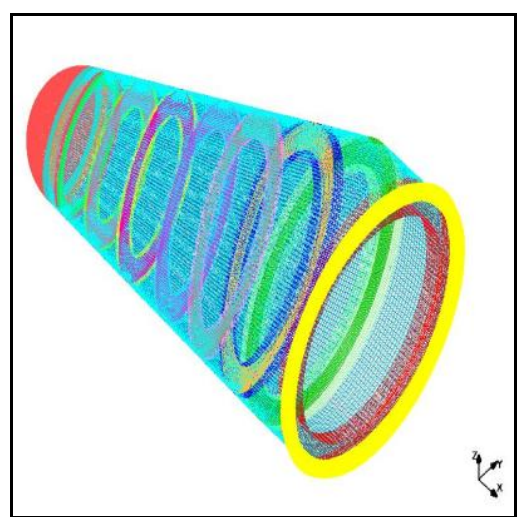

Fig. 3. Isometric View of Slanted Strapon Nose Cone 


\section{Optimization}

Optimization of structural component is done based on the static and dynamic analysis results of SSNC model. During the initial analysis the structure had a maximum resultant tip displacement of $3.15 \mathrm{~mm}$. Inner flange and web of I section bulkheads are showing very small stress values. So the bulkhead section are changed to $\mathrm{T}$ section and based on the buckling analysis the panels are also stiffened. The panel thickness changed to 2 $\mathrm{mm}$ with a $2.5 \times 25 \mathrm{~mm}$ stringers in the longitudinal direction of vehicle. The optimized design of bulkheads is given in Table 5 and the sections are updated in the finite element model.

Table 5. Optimized Design of Bulkheads

\begin{tabular}{|l|l|l|l|l|}
\hline Section & $\mathbf{b}_{\text {opt }}(\mathbf{m m})$ & $\mathbf{t}_{\mathbf{f}}(\mathbf{m m})$ & $\mathbf{D}(\mathbf{m m})$ & $\mathbf{t}_{\mathbf{w}}(\mathbf{m m})$ \\
\hline BH1 & 140 & 6 & 140 & 4 \\
\hline BH2 & 165 & 6 & 130 & 4 \\
\hline BH3 & 150 & 4 & 150 & 3 \\
\hline BH4 & 95 & 4 & 140 & 3 \\
\hline BH5 & 95 & 4 & 140 & 3 \\
\hline BH6 & 95 & 4 & 140 & 3 \\
\hline BH7 & 100 & 4 & 150 & 3 \\
\hline BH8 & 75 & 3 & 75 & 3 \\
\hline BH9 & 75 & 3 & 50 & 3 \\
\hline
\end{tabular}

\section{Analysis}

\subsection{Linear Static Analysis}

The optimized structure is used for the liner static analysis. Maximum resultant tip displacement is 2.7 $\mathrm{mm}$ and the resultant displacement contour is shown in Fig. 4(a). The influence of pressure acting on structure is more in AE ring panel so a maximum von - Mises stress of $46.1 \mathrm{~N} / \mathrm{mm}^{2}$ seen in this region. The maximum axial and shear stress on this panel is $12.8 \mathrm{~N} / \mathrm{mm}^{2}$ and $26.13 \mathrm{~N} / \mathrm{mm}^{2}$ respectively. The stress pattern on bulkheads shows that the loads are transferred from panel to bulkheads effectively. The maximum stress values are occurred in bottom end bulkhead in the high pressure region as shown in Fig. 4(b).
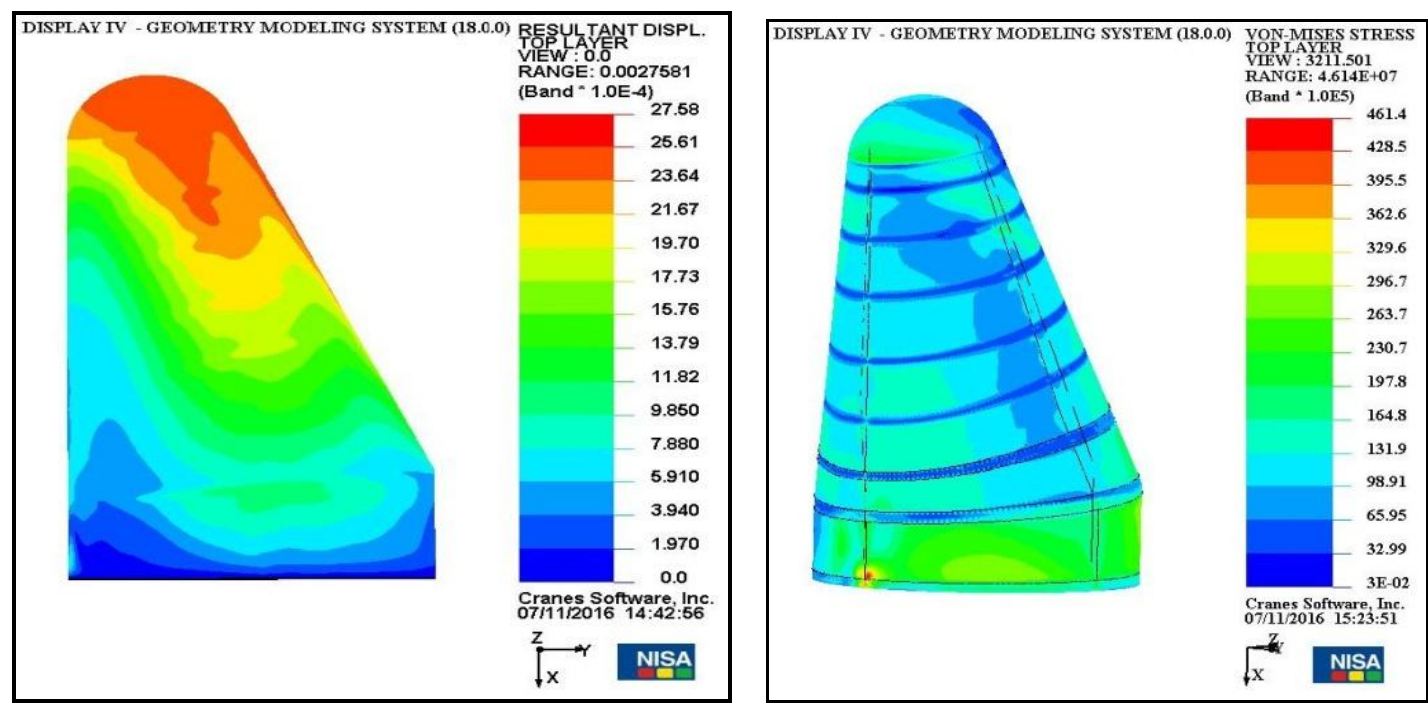

Fig. 4. (a) Resultant Displacement Contour of structure; (b) von - Mises Stress Distribution on Structure

\subsection{Buckling Analysis}

The buckling load factors are estimate to verify the maximum load on SSNC can support before it becomes elastically unstable or collapses. Fig. 5(a) shows that three percentage additional capacity is available for the structure against buckling failure. The failure of structure will occur due to local buckling of panel.

\subsection{Free Vibration Analysis}

Free vibration analysis is carried out to estimate the natural frequencies of SSNC. Natural frequency of the system is $69.8 \mathrm{~Hz}$ is shown in Fig. 5(b). 

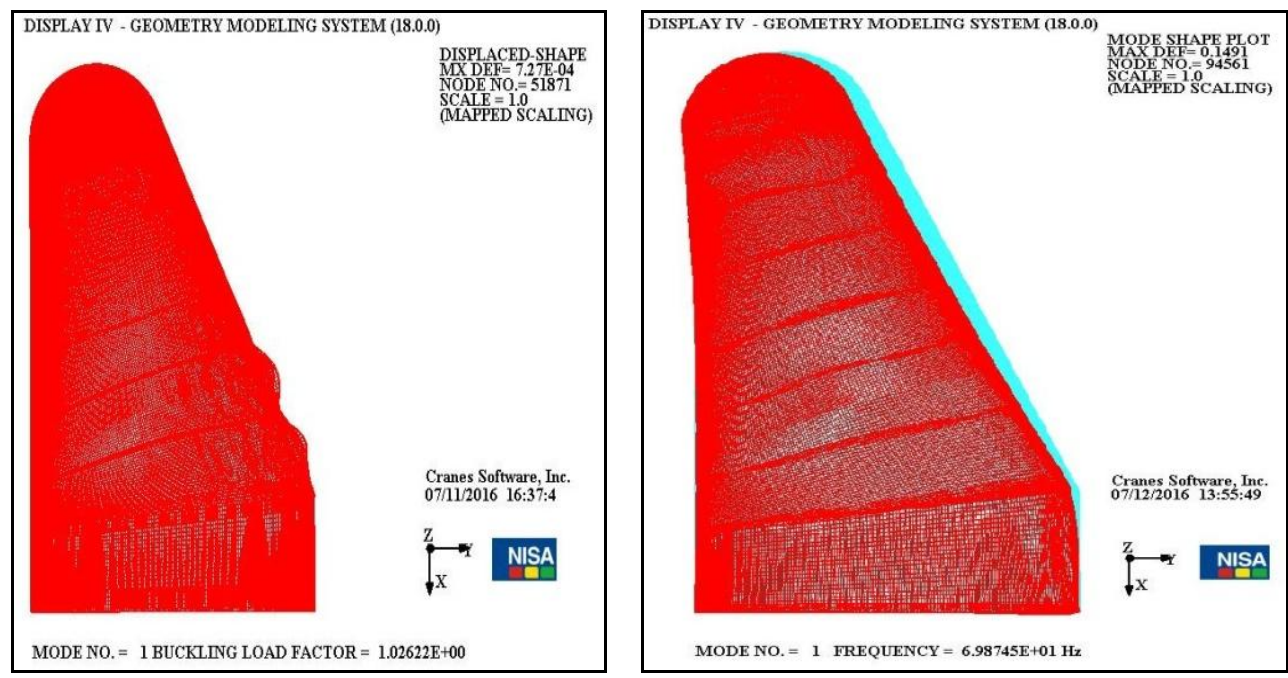

Fig. 5. (a) Buckling mode shape; (b) Mode shape of frequency $69.87 \mathrm{~Hz}$

\section{Fastener Design}

In SSNC $100^{\circ}$ countersunk head rivet made of V65 material, having higher shear strength compared to other aluminium alloys is used as fasteners. Each bulkhead is riveted to panel with CSK head rivets of $4 \mathrm{~mm}$ diameter. Pitch at each location varies according to no. of rivets per metre and the loads acting per unit width as given in Table 6 . The rivets are designed with higher margins so as to satisfy safety against different modes of failure.

Table 6. Summary of Rivet Design

\begin{tabular}{|l|l|l|l|l|}
\hline Location & $\begin{array}{l}\text { Diameter of } \\
\text { Rivet }(\mathbf{m m})\end{array}$ & $\begin{array}{l}\text { No of } \\
\text { Rows }\end{array}$ & $\begin{array}{l}\text { Pitch } \\
(\mathbf{m m})\end{array}$ & $\begin{array}{l}\text { No. of } \\
\text { Rivets/m }\end{array}$ \\
\hline BH1 & 4 & 2 & 63 & 16 \\
\hline BH2 & 4 & 2 & 63 & 16 \\
\hline BH3 & 4 & 2 & 63 & 16 \\
\hline BH4 & 4 & 2 & 63 & 16 \\
\hline BH5 & 4 & 2 & 63 & 16 \\
\hline BH6 & 4 & 2 & 60 & 17 \\
\hline BH7 & 4 & 2 & 63 & 16 \\
\hline BH8 & 4 & 2 & 58 & 17 \\
\hline BH9 & 4 & 2 & 58 & 17 \\
\hline
\end{tabular}

\section{Results and Discussion}

The optimized nose cone panels, bulkheads and longerons are satisfying the requirements for stability under design loads. An integrally stiffened panel of $2 \mathrm{~mm}$ thickness with stringers of $2.5 \times 25 \mathrm{~mm}$, optimized bulkheads and longerons are sufficient to prevent the buckling and failure stress. A mass computation is carried to check the minimum weight concept of integrally stiffened panel construction. The analysis results shows that there is an 8.5\% reduction of mass compared to the metallic nose cone structure of similar geometric configuration by a combination of stiffened skin with bulkheads and isogrid type of construction.

\section{References}

[1] Military Handbook, "Metallic Materials and Elements for Aerospace Vehicle Structures", Department of Defence, United States of America, (1998).

[2] Michael Niu, "Airframe Stress Analysis and Sizing”, Hong Kong Conmilit Press Ltd., (1999).

[3] Warren C. Young and Richard G. Budynas, "Roark's Formulas for Stress and Strain”, McGraw-Hill Publishing Company, (2002).

[4] David W.A Rees, "Mechanics of Optimal Structural Design Minimum Weight Structures", John Wiley and Sons Publications, (2009).

[5] ISRO Design Manual, "Design data - Fasteners and Circlips", VSSC Thiruvananthapuram, (2005)

[6] Michael Chun Yung Niu, “Airframe Structural Design", Technical Book Company, (1989).

[7] T.H.G. Megson, "Aircraft Structures for Engineering Students", Butterworth Heinmann Publishers, (1990).

[8] T.H.G Megson, "An Introduction to Aircraft Structural Analysis", Elsevier Butterworth Heinmann Ltd., (2007) 